\title{
Genetic counselling in the beta-thalassaemias
}

\author{
Adonis S. loannides \\ Medical School, University of Nicosia, Cyprus
}

\begin{abstract}
The beta-thalassaemias are very important genetic disorders of haemoglobin synthesis and are amongst the commonest monogenic disorders. In view of the severity of beta-thalassaemia major, a number of screening programmes have been developed aimed at reducing the number of individuals born with the condition. Genetic counsellingplays a vital role in this process supporting the successful implementation of screening and delineating available options to at risk individuals. This review assesses the contribution of genetic counsellingat each stage of this process in the context of new diagnostic techniques and therapeutic options and discusses some of the more challenging aspects such as genotype/ phenotype correlation and coinheritance of other genetic conditions or genetic modifiers.
\end{abstract}

\section{Introduction}

Adult haemoglobin ( $\mathrm{HbA}$ ) has two alpha globin polypeptide chains and two beta chains. Mutations in the genes encoding these polypeptide chains caninterfere with their synthesis and the function of haemoglobin. The type of mutation will determine the likely phenotypic consequences. In one of the best described monogenic disorders of haemoglobin synthesis, the recessively inherited sickle cell anaemia, a single missense mutation in the HBB gene, which encodes the haemoglobin beta chain, results in the substitution of the sixth amino acid from glutamic acid to valine. The resulting haemoglobin ( $\mathrm{HbS})$ is prone to crystallise under conditions such as hypoxia leading to increased red cell fragility, haemolysis and other complications.The thalassaemias, on the other hand, are autosomal recessive conditions caused by a spectrum of mutations that interfere with the synthesis of the globin chains resulting in anaemia. Alpha-thalassaemia is caused by mutations in the HBA1 and HBA2 genes leading to deletion or dys-

Correspondence: Adonis S. Ioannides

(C) Copyright A.S. Ioannides, 2013

Licensee PAGEPress, Italy

Thalassemia Reports 2013; 3(s1):e35

doi:10.4081/thal.2013.s1.e35

This article is distributed under the terms of the Creative Commons Attribution Noncommercial License (by-nc 3.0) which permits any noncommercial use, distribution, and reproduction in any medium, provided the original author(s) and source are credited.

Parts of this work were presented at the

"3rd Pan-European Conference on Haemoglobinopathies and Rare Anaemias", Limassol (Cyprus), 24-26 October 2012. function of the alpha globin alleles with the most severe phenotype (Haemoglobin Bart disease) being caused by the involvement of all four alleles (1). In beta-thalassaemias, the homozygous or compound heterozygous state is associated with a variable level of impairment of beta globin chain synthesis resulting in an imbalance between the alpha and non-alpha chains available for haemoglobin synthesis. The precipitation of unassembled alpha chains results in damage to the erythroid precursors and anaemia (2).

When both alleles are mutated in beta-thalassaemia, genotype/ phenotype correlations are important as the presence of milder mutations may ameliorate the alpha/ non-alpha chain imbalance leading to a milder phenotype. The result is a phenotypic spectrum ranging from the severe, transfusion-dependent beta-thalassaemia major to the milder thalassaemia intermedia (3). Other genetic variants influencing the expression of other types of globin chains can also lead to thereduction of the level of alpha/ non-alpha imbalance and lead to a milder phenotype. These include coinheritance of mutations in the alpha globin alleles leading to reduction of alpha globin levels as well as variants influencing the expression of other types of globin chains (such as gamma chains) leading to higher levels of fetal haemoglobin ( $\mathrm{HbF}, \alpha 2 \gamma 2)$. The extent to which genotype or presence of modifying factors can be used in prognostication will be reviewed.The severity of the beta-thalassaemia phenotypes and the high prevalence of the condition in different populations has led to the development of a number of successful population screening programmes aimed at reducing the number of individuals born with the condition. These programmes have targeted at risk populations andtheir success relies on the individuals involved receiving appropriate information on the nature, inheritance and consequences of these diagnoses so that they can make informed decisions usually relating to reproductive choices. This process is collectively known as genetic counselling. This review will assess the role and use of genetic counsellingin relation to beta-thalassaemia.

\section{Genetic counselling in the context of carrier screening}

Carrier screening was introduced in countries with high prevalence of beta-thalassaemia (Mediterranean, Middle East, Indian subcontinent) and has also been used in countries such as the United Kingdom and Canada where some communities are considered at risk in view of their ethnic background (4). Population screening can be delivered in a number of different ways. The main aspects to be considered in the design of such a programme are the timing of screening, the provision of relevant information and education, the process of obtaining informed consent, the voluntary or mandatory nature of screening and the associated genetic counselling (5). It should be pointed out however that guidelines exist stressing the significance of informed consent and that genetic testing of individuals should not be compulsory (6).

In terms of timing, screening has been offered to high-school stu- 
dents in their teenage years, at the premarital stage or in the context of antenatal screening. In the case of antenatal screening, such as the one available in the United Kingdom, one of the main drawbacks is that the choices offered to carriers are rather limited compared to those that would have been available in the preconception period. Furthermore, the screening is often done in conjunction with an array of other antenatal tests and this can impact on issues such as education and informed consent (7). Premarital screening, such as the one used in Cyprus, gives a wider range of options to those involved and in the countries in which it has been implemented it has been successful in identifying the individuals at risk $(8,9)$. Voluntary screening of high school students has been supported by the provision of education about beta-thalassaemia and has generally been associated with high uptake, levels of acceptance and subsequent recollection of the relevant information $(10,11)$.

The issue of informed consent is a significant one. It should be pointed out that educating the public through public health campaigns and providing specific information are prominent features in programmes that are considered mandatory, such as the Iranian one (12) or quasi-mandatory ones as in the case in Cyprus. Interestingly, the voluntary antenatal screening programme introduced by the National Health Service in the United Kingdom is not universally associated with sufficient information being given to the women screened. (7). This may reflect the fact that routine antenatal Full Blood Count analysis is used in the first instance as the screening tool and it may be difficult to discern this specific role from the rest of the assessments carried out at that stage. These issues highlight the importance of appropriate education and informed consent of those screened. Overall, however, the post screen component of the genetic counselling is provided at a satisfactory level in the majority of cases.

\section{Available options}

Experience from long -running screening programmes has demonstrated a very significant reduction in the numbers of new cases of betathalassaemia (13). At the same time, the experience from counties with a premarital screening requirement suggests that screening has no significant impact on the choice of partner. The main option, then, of couples at risk of having children affected by beta thalassaemia is to proceed with prenatal diagnosis and, in the great majority of cases, termination of an affected pregnancy. The advent of molecular diagnostic techniques in prenatal diagnosis has meant that individuals identified as carriers of beta-thalassaemia must undergo molecular testing to identify the relevant mutations. The advent of preimplantation genetic diagnosis has introduced an additional option and is important for carrier parents who want to avoid having affected children but at the same time want to avoid being faced with the choice to proceed with termination of an affected pregnancy (14). The downside of preimplantation genetic diagnosis is, however, the complexity of the process and the reduced overall chances of a successful outcome. On the other hand, it may bea more relevant option for couples who may require the support of assisted reproductive techniques for reasons of subfertility.

It is, of course, inherent in any process involving informed decisions about reproductive options that some carrier couples will opt not to use prenatal diagnosis but accept the 1 in 4 chance of having an affected baby for personal, ethical or religious reasons. In a very small number of cases, prenatal diagnosis and the identification of an affected fetus may not be followed by termination of pregnancy. The role of preconception genetic counsellingis, other than explain the genetic risks and the options available, to inform about the implications of the diagnosis and the current state of play with regards to management. It ispossible that recent advances in the management of thalassaemia will have contributed to such decisions by some couples to accept the risk of having affected babies. Such choices may become more frequent as beta-thalassaemia is gradually being transformed into a chronic but manageable condition. Finally, the availability of the specific thalassaemia genotype in carrier couples may also influence reproductive choices. Specifically, the presence of milder mutations in both partners may be associated with the risk of the milder thalassaemia intermedia (15). Although, by definition, not dependent on regular transfusions, this is still associated with significant morbidity and every effort must be made to inform the couples involved (16). The challenges of genetic counsellingin this context are further complicated by the influence of other genetic modifiers on the emerging phenotype resulting in a wide range of associated severity making prognostication difficult.

\section{Genotype/phenotype correlations}

What underlies the anaemia in beta-thalassaemia is the imbalance between alpha and non-alpha globin chains with the resulting precipitation of excess alpha chains and damage to the erythroid precursors. It follows that any genetic or environmental factor that reduces this imbalance may contribute to a milder phenotype. The term genetic modifiers is used to describe the influence of genetic variation on the emerging phenotype in thalassaemia (2). The nature of the mutation of the beta-thalassaemia alleles has been described as a primary modifier. More than 200 mutations have been described in the HBB gene interfering with different aspects of gene function and these mutations show characteristic regional trends $(17,18)$. It is not surprising that milder mutations that do not abolish beta globin synthesis would be associated with a milder phenotype. In fact, the severity of individual mutations has been described in terms of their effects on heterozygote carriers. Mutations that have been associated with no discernible haematological abnormality in the heterozygote state have been described as silent mutations (19). A homozygote or compound heterozygote of two silent or mild mutations is likely to be associated with thalassaemia intermedia. The difficulty arises in cases of compound hererozygosity of mild/ silent and a more severe mutation where the phenotypic variation is marked making any attempt to predict phenotype very challenging. Secondary modifiers are genetic variations in genes other than the beta globin one (20). Mutations in the alpha globin locus associated with alpha-thalassaemia and variants that promote the expression of the gamma globin gene both reduce the alpha/ non-alpha imbalance and lead to a milder phenotype (21). Such modifiers can account for the fact that individuals sharing homozygosity or compound heterozygosity of identical severe $\beta 0$ alleles show significant variation in the resulting phenotype ranging from severe transfusion-dependent beta-thalassaemia major to much milder phenotypes $(2,22)$. The situation is further complicated by the identification of other modifying loci using genome wideassociation studies $(21,23)$. In terms of using the genotype to inform the process of genetic counsellingand to predict phenotype, it would be fair to say that this is currently of rather limited practical use, applying to cases involvinga combination ofmild mutations.

\section{Practice in Cyprus}

In Cyprus, carrier detection is centralized in a specialized screening laboratory and is based on haematological screening and quantitative haemoglobin analysis. In view of the high prevalence of the carrier state, individuals can essentially refer themselves for screening as can members of families with affected individuals. Through the population screening programme, couples seeking a marriage licence through the 
church authorities will be referred to the centre for screening. More recently, and in view of the increasing numbers of civil ceremonies taking place on the island, civil authorities inform couples about the importance of screening at the stage of application. The couples involved are informed about the results directly by the laboratory and, when appropriate, are referred for counselling to the thalassaemia centre. Counselling is given to carriers of beta and alpha-thalassaemia as well as sickle cell anaemia. Counselling covers issues such as the nature of the diagnosis and its implications and the available options in terms of family planning. It is important to point out that counsellingis carried out on the basis of haematological testing and not genotyping. In the case of two beta-thalassaemia carriers, the 1 in 4 chance of having an affected child is discussed as are the options available to the couple. The option of prenatal diagnosis is taken up by most couples in this situation although there are increasing numbers of couples opting for preimplantation genetic diagnosis. Current figures suggest there are about 25-30 annual requests for preimplantation genetic diagnosis compared to about 120 requests for prenatal diagnosis. Both these techniques rely on identification of the HBB mutations involved and this analysis is performed at the specialist laboratory at the Cyprus Institute of Neurology and Genetics. The nature of the mutations identified is reported back to the thalassaemia centre and further, more focused counsellingcan then be provided based on the specific genotype. This is usually relevant in the case of mild or silent mutations (see primary modifiers above) although pitfalls in screening should be borne in mind such as the potential of missing a carrier of a silent mutation on haematological testing (19). The coinheritance of mutations in the alpha globin alleles is also discussed if initial screening also suggested the need for genotyping of the alpha globin locus. Interestingly, however, the use of such genotype/ phenotype correlations to inform counsellingis rather limited. This reflects, on the one hand the difficulty in predicting phenotype in many of the cases and on the other hand the fact that most couples have essentially made up their minds about how to proceed on the basis of the initial counselling. In short, couples rarely change their initial reproductive choices following elucidation of the genotype.A very small number of affected children are born every year and they represent cases where one or both parents were not screened or rarely because of the decision of the couple to avoid prenatal diagnosis or even to continue with an affected pregnancy.

\section{Conclusions}

Screening programmes and effective counsellingof at risk individuals have resulted in a significant reduction in the incidence of betathalassaemia major although significant regional variations remain. The predominant practice has been the use of prenatal diagnosis to terminate affected pregnancies and prevent the birth of affected children although the introduction of preimplantation genetic diagnosis offers alternative choices to the couples involved. Our in depth understanding of the molecular basis of the beta-thalassaemias and the potential role of modifiers may allow better prediction of phenotype. This approach coupled with continuing advances in the clinical management of the beta-thalassaemias will support and improve the quality of genetic counsellinggiven to at risk individuals. Attempts, however, to reliably predict phenotype based on genotype are hampered by the complexity of the interaction of the various modifying factors.

In conclusion, screening programmes supported by appropriate genetic counselling and involving informed decisions by those involvedshould continue to be implemented around the world. Continuing research may give us further insights into the molecular interplay of the various genetic and environmental factors that determine the clinical manifestations of thebeta-thalassaemias allowing for more comprehensive genetic counselling.

\section{References}

1. Chui DH, Boehm CD, Higgs DR, Cutting GR (1998) Hydropsfetalis caused by alpha-thalassaemia: an emerging health care problem. Blood 91: 2213-2222.

2. Weatherall DJ (2001) Phenotype-Genotype Relationships in Monogenic Disease: Lessons from the Thalassaemias. Nat Reviews 2: $245-255$

3. Taher AT, Musallam KM, Cappellini MD (2009) Thalassaemia Intermedia: an Update. Med J Haem Infect Dis 1 (1).

4. Zlotogora J (2009) Population programmes for the detection of couples at risk for severe monogenic genetic diseases. Hum Genet 126: 247-253.

5. Cousens NE, Gaff CL, Metcalfe SA, Delatycki MB (2010) Carrier screening for Beta-thalassaemia: a review of international practice. Eur J Hum Genet 18: 1077-1083.

6. Marteau TM, Dormandy E. Michie S (2001) A measure of informed choice. Health Expect 4: 99-108.

7. Ahmed S, Green J, Hewison J (2005) Antenatal thalassaemia carrier testing: women's perceptions of 'information' and 'consent'. J Med Screen 12: 67-77.

8. Angastiniotis M, Kyriakidou S, Hadjiminas M (1986) How thalassaemia was controlled in Cyprus. World Health Forum 7: 291-297.

9. Cowan RS (2009) Moving up the slippery slope: Mandated Genetic Screening on Cyprus. Am J Med Genet, Part C (Sem Med Genet) 151C: 95-103 Locock L, Kai J (2008) Parents' experiences of universal screening for haemoglobin disorders: implications for practice in a new genetics era. Br J Gen Pract 58: 161-168.

10. Cao A, Congiu R, Sollaino MC, Desogus MF, Demartis FR, Loi D, Cau M, Galanello R (2008) Thalassaemia and glucose-6-phosphate dehydrogenase screening in 13- to 14-year-old students of the Sardinian population: preliminary findings. Community Genet 11: 121-128.

11. Mitchell JJ, Capua A, Clow C, Scriver CR (1996) Twenty-Year Outcome Analysis of Genetic Screening Programmes for Tay-Sachs and $\beta$-Thalassemia Disease Carriers in High Schools. Am J Hum Genet 59:793-798.

12. Samavat A, Modell B (2004) Iranian national thalassaemia screening programme. BMJ 329: 1134-1137.

13. Angastiniotis MA, Hadjiminas MG (1981) Prevention of thalassaemia in Cyprus. Lancet 1: 369-371.

14. Petrou M (2009) Preimplantation genetic diagnosis. Haemoglobin 33 Suppl 1:S7-S13.

15. Verma IC, Kleanthous M, Saxena R et al (2007) Multicentre Study of the Molecular Basis of Thalassemia Intermedia in Different Ethnic Populations. Haemoglobin 31(4): 439-452.

16. Musallam KM, Taher AT, Rachmilewitz EA (2012) betaThalassaemia Intermedia: A Clinical Perspective. Cold Spring Harbor Perspectives in Medicine 2(7): 1-15.

17. Ansari SH, Shamsi TS, Ashraf M et al (2011) Molecular epidemiology of $\beta$-thalassemia in Pakistan: far reaching implications. Int $\mathbf{J}$ MolEpidemiol Genet 2(4): 403-408.

18. Baysal $\mathrm{E}$, Indrak K, Bozkurt $\mathrm{G}$ et al (1992) The $\beta$-thalassemia mutations in the population of Cyprus. Br J Haem 81: 607-609.

19. Bianco I, Cappabianca MP, Foglietta E et al (1997) Silent Thalassaemias: Genotypes and Phenotypes. Haematologica 82: 269-280.

20. Galanello R, Sanna S, Perseu L et al (2009) Amelioration of Sardinian $\beta 0$ thalassemia by genetic modifiers. Blood 114 (18): 3935-3937.

21. Uda M, Galanello R, Sanna S et al (2008) Genome-wide association study shows BCL11A associated with persistent fetal hemoglobin and amelioration of the phenotype of $\beta$-thalassemia. PNAS 105(5): 1620-1625.

22. Cividalli G, Kerem H, Ezeckiel E, Rachmilewitz EA (1978) Beta 0thalassaemia intermedia. Blood 52: 345-349.

23. Farrell J, Sherva RM, Chen Z et al (2011) A 3-bp deletion in the HBS1L-MYB intergenic region on chromosome 6q23 is associated with HBF expression. Blood 117 (18): 4935-4945. 